\title{
“AGORA, QUE SOLIDÃO A MINHA”: CAMILO PESSANHA E O FIM DE SÉCULO PORTUGUÊS.
}

\author{
MARCHIORO, Camila ${ }^{1}$
}

RESUMO: Esse artigo se dedica a apresentar alguns aspectos históricos da atividade literária de Camilo Pessanha em Portugal antes de sua ida à China. São descritas as suas concepções sobre poesia, sua autocrítica e conexões com outros autores da época. O artigo ainda contempla uma revisão crítica do modo como Pessanha foi abordado no decorrer dos séculos a partir da sua relação com o Simbolismo. Tomando como base algumas composições do poeta, tenta-se problematizar a sua classificação como um simbolista estreito, chamando a atenção para outros aspectos de sua escrita que se relacionam com temas comuns à literatura portuguesa anterior ao Simbolismo e que se conectam à temáticas orientais as quais o poeta conheceu durante a sua vivência no Oriente. Por fim, nota-se a importância de considerar outras relações que Pessanha tenha estabelecido para além do Simbolismo, dando maior amplitude à relevância de sua contribuição poética, redimensionando os laços de sua obra.

PALAVRAS-CHAVE: Camilo Pessanha, Simbolismo, Oriente, periodização literária.

\section{“AGORA, QUE SOLIDÃO A MINHA": CAMILO PESSANHA AND THE PORTUGUESE FIN-DE-SIÈCLE.}

\begin{abstract}
This article presents some historical aspects of the literary activity of Camilo Pessanha in Portugal before his trip to China. For this, we analyze his conceptions about poetry, his self-criticism and his connections with other authors of the time. The article also contemplates a critical revision of some texts that consider his work as Symbolist. Drawing on some compositions of the poet, his classification as a narrow symbolist is questioned, calling attention to other aspects of his writing that relate to themes common to Portuguese literature prior to Symbolism and that connect to the Eastern themes that the poet met during his experience in the East. Finally, we note the importance of considering other relations that Pessanha has established beyond Symbolism, giving greater amplitude to the relevance of his poetic contribution, resizing the ties of his work.
\end{abstract}

\footnotetext{
${ }^{1}$ Doutora em Letras - Estudos Literários - pela UFPR. E-mail: camila.marchioro@ gmail.com Jangada | nr. 14, jul/dez, 2019 | ISSN 2317-4722 
KEYWORDS: Camilo Pessanha, Symbolism, East, literary periodization.

\section{INTRODUÇÃO}

Camilo Pessanha nasceu em 7 de setembro de 1867, em Coimbra. Acredita-se que tenha escrito seu primeiro poema no ano de 1885, "Lúbrica", no decorrer de seus primeiros anos do curso de Direito, feito em sua cidade natal. Neste primeiro escrito, segundo o autor António Dias Miguel em Camilo Pessanha - elementos para o estudo da sua biografia e da sua obra, 1956, são evidentes influências do poeta Cesário Verde. No início do ano de 1887 publicou no jornal Gazeta de Coimbra o poema "Madrigal”, cuja temática enfatiza a frieza de uma mulher, abrindo espaço para uma das imagens mais recorrentes de sua obra. Ainda no mesmo ano, também na Gazeta de Coimbra, publicou "Soneto de Gelo", poema que concentra muitos temas que viriam a ser significativos em Clepsydra, como por exemplo a ambiência lúgubre, a obscuridade, o frio, a sensação de impotência, a anunciação da ruína, entre outros. Pode-se dizer que 1887 foi um ano bastante produtivo, pois publicou mais "Entre Gaiatos", "Crónica da alta", "Na pasta do Abel Aníbal” e compôs “Tenho sonhos cruéis n'alma doente”, "Encontraste-me um dia no caminho" e "Fez-nos bem, muito bem esta demora".2

Dado o cariz de suas primeiras publicações, evidencia-se em Pessanha o olhar mais reflexivo, pessimista e ainda que denote uma busca pela fé, como em "Soneto de Gelo": "Eu mesmo quero a fé, e não a tenho...", não há manifestações de um misticismo, atitude que marca a sua diferença em relação aos denominados Simbolistas. "Soneto de gelo" é emblemático no sentido em que marca um ponto interseccional entre a descrença na "ciência", a busca pela fé e um forte sentimento de descabimento: "O Deus, o mesmo Deus que te fez crente... / Nem saibas que esse Deus omnipotente /Foi quem arrebatou a minha crença", o que reforça o momento histórico conflituoso no qual se situava o poeta e que influenciou sobremaneira os rumos da poesia local. Todavia, não é fácil localizar Camilo Pessanha como um Simbolista, mesmo no sentido amplo e genérico do termo.

\footnotetext{
${ }^{2}$ Todos os dados referentes à biografia do poeta, incluído as datas das publicações de seus escritos esparsos, encontram-se no espólio do autor, acessível na Biblioteca Nacional de Portugal, visitado por mim em 2015. Há ainda uma cronologia do poeta elaborada por Daniel Pires no livro Correspondências, dedicatórias e outros textos: Camilo Pessanha (2012). É ainda possível acessar a mesma cronologia de Pessanha feita por Daniel Pires no seguinte link da Biblioteca Nacional: http://purl.pt/14369/1/cronologia1927.html
} 
"Soneto de gelo" oferece um entendimento preciso do cenário literário e histórico em que se colocavam as primeiras composições do poeta coimbrão. Poucos anos depois, em 1890, após uma estadia em França, outro poeta de Coimbra, Eugenio de Castro (1869-1944), publicou Oaristos, obra inaugural que deu espaço para composições poéticas muito mais livres e ousadas no que diz respeito à métrica, disposição das palavras na página do livro e uso de metáforas. Vejamos um trecho do prefácio da primeira edição:

(...) Com duas ou três luminosas exceções, a Poesia portuguesa contemporânea assenta sobre algumas dezenas de coçados e esmaiados lugares-comuns.

Tais são:

olhos cor do céu, olhos comparados a estrelas, lábios de rosa, cabelos de ouro e de sol, crianças tímidas, tímidas gazelas, brancura de luar e de neve, mãos patrícias, dentes que são fios de pérolas, colos de alabastro e de cisne, pés chineses, rouxinóis medrosos, brisas esfolhando rosas, risos de cristal, cotovias soltando notas também de cristal, luas de marfim, luas de prata, searas ondulantes, melros farçolas assobiando, pombas arrulhadoras, andorinhas que vão para o exílio, madrigais dos ninhos, borboletas violando rosas, sebes orvalhados, árvores esqueléticas, etc..

No tocante a rimas, uma pobreza franciscana: lábios rimando sempre com sábios, pérolas com cérulas, sol com rouxinol, caminhos com ninhos, nuvens com Rubens (?), noite com açoite; um imperdoável abuso de rimas em ada, ado, oso, osa, ente, ante, o, ar, etc.

No tocante a vocabulário, uma não menos franciscana pobreza: talvez dois terços das palavras que formam a língua portuguesa, jazem absconsos, desconhecidos, inertes, ao longo dos dicionários, como tarecos sem valor em lojas de arrumação.

Tais os rails por onde segue, num monótono andamento de procissão, o comboio misto que leva os Poetas portugueses da actualidade à gare da POSTERIDADE, Poetas suficientemente tímidos para temerem o vertiginoso correr do expresso da ORIGINALIDADE. (CASTRO, 1985, p. 89-95).

A crítica de Eugénio de Castro dirigida aos poetas românticos e realistas de seu tempo demonstrou a sua acurada relação com o movimento simbolista francês, além de que sua obra evidenciou o clima de inquietação finissecular (que em Portugal se agravara com os ecos do 
“Ultimato Inglês"). ${ }^{3}$ O poeta estava profundamente conectado com a proposta do Simbolismo e, portanto, seu livro Oaristos, anterior à publicação da revista Arte (1895), já trazia fortes os traços de um novo estilo:

(...) Este livro é o primeiro que em Portugal aparece defendendo a liberdade do Ritmo contra os dogmáticos e estultos decretos dos velhos prosodistas. As ARTES POÉTICAS ensinam a fazer o alexandrino com cesura imutável na sexta sílaba. Desprezando a regra, o Poeta exibe alexandrinos de cesura deslocada e alguns outros sem cesura. Tal fizeram, em França, Francis VieléGriffin e Jean Moréas. Os alexandrinos são lançados em parelhas, mas os últimos quatro versos de cada Poema têm (tal se faz nos tercetos) suas rimas cruzadas. Salvo erro, é a primeira vez que assim se corta o alexandrino. Pela primeira vez, também, aparece a adaptação do delicioso ritmo francês, rondel. Introduz-se o desconhecido processo da aliteração: veja-se o poema XI e muitos versos derramados ao longo desta silva. Ao contrário do que por aí se faz, ornaram-se os versos de rimas raras, rutilantes: na mais extensa composição, a composição IV, que tem cento e sessenta e dois alexandrinos, não se encontra uma única rima repetida. (Idem, ibidem).

Dado o conteúdo do prefácio acima, percebe-se o que os críticos António José Saraiva e Óscar Lopes afirmaram acerca do simbolismo português: este estava marcado "por preocupações versificatórias e verbais" (SARAIVA; LOPES, 2001, p. 976). Ainda que o livro de Castro tenha sido uma oposição aos lugares-comuns que dominavam a poesia portuguesa, o poeta não adotou os princípios filosóficos dos simbolistas franceses. Nota-se em seus poemas especialmente o elemento inovador do estilo e dos temas, rompendo com o velho culto romântico da natureza, com o idealismo amoroso e com o exagero emotivo. O livro não logrou grandes aclamações, entretanto o movimento teve boa adesão de jovens poetas, como Alberto de Oliveira, Justino de Montalvão, D. João de Castro, António Nobre, João Barreira - maiores expoentes do movimento, segundo Trindade Coelho (COELHO apud RAMOS, 1947, p. 31) entre outros dos quais se destaca Alberto Osório de Castro, amigo de Camilo Pessanha.

Naquela época, segundo José Carlos Seabra Pereira em "Camilo Pessanha e a transmutação simbolista":

\footnotetext{
${ }^{3}$ Eugénio de Castro fundou em 1895, com Manuel da Silva Gaio, a revista internacional Arte, da qual foi diretor entre 1895 e 1896 . Na revista foram publicados textos de escritores portugueses e estrangeiros da época, tais como Gustave Khan, Verlaine e Mallarmé.
} 
Pessanha escreve contos e poemas para periódicos secundários e entremeia ficção com digressão impressionista ou crítica literária nas "Crónicas da Alta"; mas logo depois, em 1889, fica à margem da emergência da arte "novista" no despique entre a Boémia Nova e Os Insubmissos. Então, além de Osório de Castro fazer sair (agora no seu jornal O Novo Tempo de Mangualde) mais "Crónicas da Alta" e episódicos poemas de Pessanha, é decerto graças à ligação com ele que outros poemas de Camilo podem surgir também em órgãos nefelibatas como O Intermezzo portuense. (PEREIRA, 1995, p. 129).

Seabra Pereira salienta ainda que o nome de Pessanha passou a figurar já na primeira tentativa de fixação de um cânone "novista", quando o grupo renovador do Porto redigiu Os Nefelibatas. Pessanha enviara para publicação um bom número de composições suas, o que de algum modo contraria a ideia mitificada de que não anotava absolutamente nada. Outro ponto levantado por Seabra Pereira diz respeito à relação que o escritor manteve com os grupos literários que o circundavam:

importa considerar que tem sido exagerada a distância que Pessanha desde jovem se teria mantido dos grupos literários coetâneos; importa reconhecer que, desde os inícios, o escritor se revela, pela índole dos seus textos, não alheado das novas orientações estéticas, mas próximo da plena sintonia com essas tendências. (Idem).

Contribuiu assim, entre alguns contos, com os já citados poemas "Lúbrica", "Madrigal”, "Na pasta do Abel Aníbal", também "Caminho", "Interrogação", "Crepuscular", "Estátua", "Soneto" e "Madalena", além de "Soneto de gelo". Tendo, em 1888, reprovado o quarto ano do curso de Direito e com grave doença nervosa que o impediu de se matricular na Faculdade, escreveu a seu primo José Benedito:

Mando o número disso [revista $A$ Crítica], os únicos saídos, por enquanto. Acredita que não tem sido falta de consideração não tos mandar até hoje. Em primeiro lugar nada tenho com a direção do papelucho; em segundo lugar mesmo que tivesse, envergonhava-me da companhia... e de mim. Mando-tos porque mos pedes; vão os únicos exemplares com que fui contemplado, e ainda bem que me tiras de casa esse remorso. (PESSANHA, In: Correspondência, dedicatórias e outros textos, 2012, p. 241). 
O tom da carta demonstra o desapreço do poeta por suas criações e também o seu distanciamento em relação aos criadores da revista, o que reitera o estudo de Seabra Pereira a respeito de Eugénio de Castro ter sido de suma importância para as publicações de Pessanha e reitera ainda o isolamento do poeta em relação aos círculos literários da época. Na sequência da carta ao primo, Camilo Pessanha argumenta sobre a situação em que foram escritos os tais poemas e contos:

(...) nas férias grandes passadas me luziu a ideia de duas séries, uma de prosa outra de verso, que deixaram a perder de vista todos os meus feitos de até então.

A prosa seria contos e chamar-se-ia "Solidões", não minha, mas das figuras: estados de espírito diverso, apreendidos no olhar que uma avó estende pelo seu passado, no tremor de lábios de um velho na presença dos quinze anos de uma rapariga que o desdenha, ingenuamente impudica, no corar de qualquer burguesinha, que vê da sua janela o último namorado que lhe mentiu, etc.

$\mathrm{O}$ verso não teria nome. Dividi-lo-ia em duas partes. A primeira havia de ser a luta pela realização do prazer, com a certeza de lutar por uma aspiração falsa. (...) A outra parte - exceções, consolações, aniquilamentos parciais do eu, estases, espasmos e modorras. (Idem).

Seriam essas as ideias de Pessanha no final do século XIX. Segundo a carta, cerca de dois anos antes ele repudiara alguns escritos seus em detrimento da sua ideia para as duas referidas séries.

Na carta, Camilo Pessanha relata ter conhecido os defeitos de sua criação e por isso “deitou” os poemas no saguão, mas seu condiscípulo Lomelino os teria aproveitado e os "levou" (Idem, p. 242). Suas contribuições "às avessas" naquele momento teriam sido "Na pasta do Abel Aníbal", "Crónica da alta" e "Dia aziago". O condiscípulo provavelmente se trata de Lomelino de Freitas, redator, ao lado de Armelim Júnior, da revista A Crítica: ciência, literatura e crítica, e em 1895 redator da revista Boémia velha (CARVALHO PRATA, 2006, p. 74). A revista Boémia velha satirizava a revista Boémia nova, nas palavras do historiador da educação Manuel Alberto Carvalho Prata em Imprensa estudantil coimbrã:

Neste ano de 1889, duas revistas coimbrãs, Insubmissos e Boémia Nova, disputavam, no âmbito da literatura portuguesa, a primazia na introdução de 
novas experiências rítmicas e estilísticas, fazendo eco de nomes sonantes das letras francesas.

A revista Boémia Velha (nome de oposição a Boémia Nova) aparece enquadrada nesta polémica. Daí que o seu conteúdo seja, fundamentalmente, uma crítica, por vezes parodística, à revista Boémia Nova. Fazem-se críticas e reflexões aos escritos de Alberto de Oliveira, a quem tratam por "Albertinho de Oliveira" (p. 2, col. 1), Carneiro de Moura, Alberto Osório de Castro e António Nobre, entre outros. (CARVALHO PRATA, 2006, vol I, p. 75).

No ano que se segue à "contribuição" de Pessanha para A Crítica, o poeta viria a estreitar seus laços com Alberto Osório de Castro, colega na Faculdade de Direito e diretor do periódico de Mangualde O Novo tempo, onde publicou "Crônica da alta", "Crepuscular" e "Interrogação" (PIRES, 2012, p. 39). Uma vez que Pessanha tornara-se grande amigo de Osório de Castro e dado o teor satírico de Boémia velha (cuja redação Lomelino de Freitas integrava) em relação à revista com a qual o amigo Osório colaborava, era muito possível que Pessanha, já em 1888, tenha se manifestado sinceramente ao dizer ao primo que caso tivesse alguma relação com a diretoria de A Crítica "envergonhava-me da companhia... e de mim" (PESSANHA, 2012, p. 241). Sendo assim, é plenamente justificável que Camilo Pessanha tenha incluído na primeira publicação da Clepsydra em 1920, apenas um dos seus poemas escritos antes de 1894 (ano em que partiu para Macau) - o poema em questão é "Estátua".

\section{SOBRE POETAS E POESIA}

Pode-se dizer que, de algum modo, Pessanha partilhava de algumas das ideias de Eugénio de Castro, pelo que se pode perceber das ásperas palavras do poeta da Clepsydra sobre o livro de António Fogaça, Versos da mocidade, editado em Coimbra em 1887:

A obra de Fogaça é suspensa sobre as nuvens. Ora é cheia de metáforas gratuitas e obscuras, que o leitor não lhe compreende o sentido ("Ninguém percebeu"), ora, pelo contrário, cai no excesso oposto, "no pior do romantismo decadente, pretensioso, mascarado de frases novas".

As livrarias enchem-se assim de minúsculos volumes, como o de Fogaça, onde em cem páginas se esgota o estéril impulso lírico da mocidade. Destinados a amarelecer nas montras dos livreiros. (PESSANHA, Março de 1888.). 
José Carlos Seabra Pereira, no mesmo artigo supracitado, diz sobre o posicionamento de Pessanha em relação aos Versos da Mocidade: ${ }^{4}$

com congruência, ao subscrever desassombrada crítica dos Versos da Mocidade dum A. Fogaça então muito festejado, mostra-se convictamente oposto aos epigonismos românticos e às suas mesclas com perfunctórias assimilações (descritivas ou narrativas) do Parnasianismo." (PEREIRA, 1995, p. 130).

O que reafirma uma possível simpatia de Camilo Pessanha pelos ares simbolistas que pairavam em Coimbra naquele período é outro texto que escreveu, tempos depois, sobre o livro Flores de coral, do amigo Alberto Osório de Castro. Este em tom notadamente diverso daquele feito ao A. Fogaça:

Só poucos têm uma vocação artística sincera e duradoura, que sobrevive ao embate da vida real. Entre estes é de incluir Alberto Osório de Castro, já há muitos anos marido e pai, constrangido pela sua profissão de magistrado no Ultramar a mudanças frequentes ("através de milhares de léguas, cada uma das quais escava de repente um abismo no jardim dos seus afectos e das suas divagações entre o instante que passa e o que lhe sucede"), forçadamente longe dos círculos literários, condenado à solidão intelectual. Mas nele sobrevive irredutivelmente o poeta, porque a sua inspiração é autêntica, não alimentada "parasitariamente das falsas e convencionais emoções de uma psicologia de pacotilha, corrente na boémia dos meios chamados intelectuais". (PESSANHA apud SPAGGIARI, 1982, p. 39).

\footnotetext{
${ }^{4}$ Na edição de 1945 os poemas da Clepsydra foram divididos entre "Sonetos" e "Poesias", contrariando o que Pessanha deixara claro no texto sobre Fogaça:
Preferiu que saísse tudo: reuniu todos esses versos num título que pudesse abrangê-los, embora não lhes precisasse uma característica, não significasse coisa nenhuma: Mágoa e risos, por exemplo...
Bem claro, que na Mágoa e risos podia ter incluído as Orações do Amor!
Depois, como esta última parte ficava desproporcionada, e continha 62 sonetos (64 páginas de impressão) subdividiu a Mágoa e risos em sonetos e não sonetos. (PESSANHA, "Crónica da Alta [Versos da Mocidade, de António Fogaça]”, In. A Crítica, 1888).

Camilo Pessanha explicita a sua predileção por um "vetor estruturante" que ordene o livro enquanto obra de arte. De modo que se pode supor que na Clepsydra de 1920 o poeta tenha prezado por isso. Entretanto a crescente descoberta de novos poemas do autor fez com que os editores procurassem novos meios de inseri-los à Clepsydra. 
O trecho coloca em relevo a preferência de Pessanha pela genuinidade do poeta e mostra a crença em que haveria um lugar de "inspiração autêntica", que se daria distante de uma "psicologia de pacotilha", insuficiente e superficial, corrente "nos meios chamados intelectuais". Tal ponto de vista está conectado com a propensão do autor para afastar-se de grupos intelectuais ou mesmo correntes de pensamento e artísticas. Desse modo, não é possível afirmar que Pessanha tenha aderido convictamente aos ideais simbolistas, mesmo que Verlaine tenha sido um de seus poetas de eleição.

Sobretudo, o que se pode afirmar, dado o teor do conteúdo do trecho acima, é que Camilo Pessanha primava pela relação íntima do poeta com a inspiração em um meio autêntico, propiciado por um contato profundo com o mais secreto do poeta. Acerca disso, a estudiosa da obra de Pessanha, a professora italiana Barbara Spaggiari, colocou:

(...) poeta tem como único objectivo o de "realizar por meio da verdade, a beleza" Este conceito da verdade, a que Pessanha alude aqui de forma breve, constitui um elemento fundamental da sua poética. A poesia, se por um lado é para ser considerada como uma arte subjectiva (a par da música, como vimos), por outro deve ser objectiva "pelos temas que lhe servem de motivo - lendas, aspectos, episódios; porém através do aspecto (e ao mesmo tempo que o esteta o apreende e investiga quantidade de beleza que pode produzir, afeiçoando-a determinada forma literária) o consciencioso observado científico, de que o esteta se duplica, interpreta fenómeno e perscruta o fundo de que o mesmo aspecto é a superfície: a natureza íntima das coisas, as relações e fatalidade dos seus destinos. Mais do que isso: no fenómeno de cada uma das aparências que interpreta, não se esquece de discriminar a participação da sua própria alma, o espelho em que se revelam”. (SPAGGIARI, 1982, p. 40).

Sendo assim, mesmo distante de um ambiente que alimentasse o fazer artístico, o escritor, enquanto artífice, tornar-se-ia princípio, meio e fim de sua própria inspiração e criação, não havendo para além disso nada mais genuíno e, consequentemente, comprobatório da "vocação artística". Salvaguarda-se, ainda, a extrema importância dada pelo poeta à solidão, o que nos permite aplicar para Pessanha o que ele mesmo afirmou acerca do amigo Alberto Osório, uma vez que também Camilo Pessanha estivera "forçadamente longe dos círculos literários, condenado à solidão intelectual”. De modo que é possível afirmar que também o 
poeta da Clepsydra fazia parte da estirpe dos poucos que "têm uma vocação artística sincera e duradoura, que sobrevive ao embate da vida real".

Camilo Pessanha se refere à vocação de modo que, para ele, ser poeta é mais que fazer versos "parasitariamente das falsas e convencionais emoções de uma psicologia de pacotilha", ser poeta é ser capaz de criar uma obra mesmo diante do mais completo isolamento, o que comprovaria a verdadeira vocação e não apenas um comportamento parasita, de imitação. ${ }^{5}$

Por tudo isso, se havia no poeta coimbrão forte relação com o simbolismo francês, notadamente no que diz respeito ao mergulho interior e à busca pela inspiração autêntica tendo como base a sua própria visão acerca do "ser poeta" - isso se deu de modo genuíno e não por vontade de cópia ou desejo de pertencimento a um grupo.

Não obstante, a crítica colocou durante anos Camilo Pessanha no mais alto patamar do simbolismo português. Andrade Muricy chegou a classificá-lo como o "Verlaine português":

Eminente simbolista foi Camilo Pessanha (1867-1926) este sim: o Verlaine português - que longamente viveu e morreu no Oriente, na velha Macau. A sua obra, compreendida no livro Clepsidra (...) abrange apenas quarenta poesias, mas de melindrosa pureza, de quase imaterialidade expressional, frequentemente como de translúcido e misterioso hermetismo. (...) Camilo Pessanha, só conhecido postumamente, foi o derradeiro poeta do simbolismo português e, sem dúvida, o maior e mais perfeito. (MURICY, 1987, p. 87).

Muricy seguia o ritmo natural de uma crítica literária que buscava sempre correspondências entre os movimentos franceses e as literaturas portuguesa e brasileira, reiterando o que notou Antonio Candido em A formação da literatura brasileira: a característica de a literatura brasileira ser um galho da portuguesa que por sua vez é um galho da francesa. São evidentes as relações entre Pessanha e o Simbolismo francês, todavia, assim como salientaram os estudiosos da obra de Pessanha, Paulo Franchetti e Gustavo Rubim, sobre a importância de desvincular a obra do poeta coimbrão de certos mitos sobre sua biografia, colocar a relação de Pessanha com o Simbolismo como ponto máximo de sua obra e ter apenas este sentido como base de análise pode ofuscar grande parte de sua poesia, notadamente aquela escrita sob o sol nascente do Oriente. Vale, portanto, mais que fazer uma retomada da história

\footnotetext{
${ }^{5}$ Lembremo-nos ainda que um dos motivos que fizeram com que Ana de Castro Osório insistisse na edição de um livro que reunisse os poemas de Pessanha foi o fato de ouvir seus versos serem recitados sem nenhum cuidado no seio da boémia portuguesa, prática que desconfigurava a real poesia de Pessanha. Sendo assim, o texto do autor da Clepsydra para o amigo Osório de Castro pode também ser lido, hoje, como um indício do que pensaria o autor daqueles que se apropriavam de versos para récita nos salões intelectuais da época.
} 
e características do movimento simbolista (direcionamento comum às teses sobre Camilo Pessanha), analisar de perto o cenário que cercava o poeta durante a sua juventude em Portugal e verificar como ele se posicionou em relação aos movimentos literários da época.

No anteriormente citado texto a A. Fogaça (que viria a morrer no mesmo ano sem terminar o curso de Direito), Camilo Pessanha deu mais uma demonstração da sua ideia de poesia. O autor escreveu em "A importância de um vetor estruturante":

Consta de tentativas. O Sr. António Fogaça, como todos os novatos em arte, não tem um princípio, uma noção, um sentimento, que o arraste conscientemente, presidindo à conceção de todas as suas obras. Impressionável e pouco atenta, a sua imaginação é vibrada desordenadamente por coisas diversíssimas: por princípios de filosofia lidos de fresco, pela sensualidade, pelo amor de uma noiva, por trechos de paisagem, pela cadência dos versos que estão mais em voga. Só à influência destes posso atribuir a maior parte dos sonetos e alguma poesia mais, (...). (PESSANHA, 1888.).

Fixemo-nos por ora no seguinte período: "a sua imaginação é vibrada desordenadamente por coisas diversíssimas (...) pela cadência dos versos que estão mais em voga”. Esta colocação demonstra que Camilo Pessanha conhecia a forma parnasiana e simbolista que pairava sobre a obra de Fogaça. Acerca do livro, afirma José Carlos Seabra Pereira em "Romantismo tardio e surto Neo-romântico no fim-de-século":

Sob a precedência do sentimento crescem e multiplicam-se os Versos da Mocidade. Nem o já apreciável apuro formal, nem alguns assomos de distanciamento chão perante vivências e mitos de matriz romântica (v.g. «Conselho amigo» e o donjuanismo) iludem a ligação de Fogaça à tradição subromântica do Portugal oitocentista. A continuidade estilística e a discursividade separam-no ainda da poesia «novista» que então estava a chegar com a sua estética da sugestão, tal como da sua abstenção artiste o separam a sátira de costumes e de mentalidades $(\ll \mathrm{O}$ frade», «O novo Visconde»). Pelo contrário, os temas e motivos associam Versos da Mocidade à nebulosa neo-romântica do fim-de-século. (PEREIRA, 1998, p. 942).

Apesar do cunho neorromântico do livro, Seabra Pereira salienta adiante alguns poemas que apresentam ar decadentista e, por fim, assinala: 
(...) a ênfase polissindética e reiterante, a variante do popularismo artístico no descante estudantil de «Para a guitarra», as hesitações com que o patente esforço de variação estrófico-rimática alcança sucessos de leveza rítmica ou de composição em anadiplose («A uma Andaluza») — mau grado poder antecipar, como notou Miranda de Andrade, alguma das inovações técnicas que Eugénio de Castro reivindicará nos Oaristos de 1890. (Idem).

Quando Pessanha referiu-se à "cadência de versos que estão mais em voga" poderia estar aludindo justamente ao ar quase simbolista da obra de Fogaça, que antecipa, de algum modo, as inovações técnicas de Oaristos. Sendo assim, pode-se entender que Pessanha, além de prezar por uma coerência temática, valorizava uma cadência condizente com o "vetor estruturante" (eixo para o livro) em lugar de seguir algum modismo. O que revela que muito provavelmente as escolhas métricas do autor de Clepsydra estejam estreitamente relacionadas à temática dos versos e de todo o livro, consequentemente. A opção de Pessanha por este procedimento se daria, nesse sentido, por fidelidade ao seu ideal de poesia e não por preocupação em estar condizente com os valores de uma escola literária. Nota-se pelo teor da redação de Pessanha ao livro de Osório de Castro, bastante posterior à apreciação ao livro de Fogaça, que os ideais poéticos do autor pouco mudaram e que seu conceito de boa poesia se formou ainda na juventude, o que certamente motivou a crítica a descartar, por muitos anos, a presença da China em sua obra.

Contudo, a posição do poeta coimbrão em relação ao livro Flores de coral mostra que embora envolto pela atmosfera literária finissecular e pelos ideais do Simbolismo que tomava formas novas em Portugal, especialmente por meio das revistas que circulavam por Coimbra à época de sua formação em Direito, a obra de Camilo Pessanha foi marcadamente influenciada pela sua experiência de autoexílio no ultramar, sua vivência a bordo de navios e sua solidão distante da pátria. Por tudo isso é que a poesia de Pessanha começou em Portugal e amadureceu em Macau, muitos de seus poemas foram reelaborados sob o sol do Oriente, o que lhes confere uma dimensão nova que excede em muitos pontos a prática do simbolismo europeu.

Não obstante todo o seu potencial afastamento da cena literária portuguesa, Camilo Pessanha foi considerado, conforme citado acima, como o maior expoente do Simbolismo em Portugal. Não sendo um romântico, tampouco um realista, dado o uso que fez de assonâncias e aliterações, como no poema "Chorai arcadas do violoncelo", e de um ritmo similar ao de Verlaine: "vim a descobrir que o ritmo dos meus decassílabos que tanto me preocupavam é o do verso de Verlaine", seria inoportuno classificá-lo de outro modo, sobretudo antes do 
surgimento da Geração de Orpheu. Todavia, percebe-se que o caso de Pessanha é muito mais complexo. Com a publicação do primeiro número de Orpheu em 1915, a classificação do autor enquanto um simbolista, embora não questionada pela crítica da época, pode ser redimensionada. Mesmo que tenha certamente lido Baudelaire, Rimbaud e Verlaine, a sua poesia é demasiado diferente do Simbolismo desses três grandes poetas franceses, sobretudo pela relação estreita com Macau e algumas línguas locais.

Quem sutilmente chamou a atenção para a difícil inserção de Camilo Pessanha nos movimentos literários de sua época foi Cecília Meireles em sua antologia Poetas novos de Portugal (1942) dirigida por Jaime Cortesão. À altura da publicação da citada antologia, Camilo Pessanha havia falecido há cerca de 16 anos, o que faz com que sua inclusão no livro seja um tanto peculiar e, de fato, o poeta é o mais antigo que consta na antologia. A autora escolheu uma série de nomes que figuravam na cena portuguesa com publicações entre os anos 20 e 40, o que inclui a Clepsydra, dada à estampa em 1920. O foco do livro de Meireles é a Geração de Orpheu de modo que no prefácio afirmou o seguinte:

Preferiu-se começar por Camilo Pessanha, por menos conhecido no Brasil, e por mais próximo do grupo de que se vai tratar.

De sensibilidade delicadíssima, a que a arte e os costumes da China onde por muitos anos viveu não deixaram de imprimir vestígios, sua obra - musical, cheia de intenções, de descontentamentos do cotidiano, do imediato, do real, é uma viagem interior frágil e arriscada. Nasce de sua poesia uma outra atmosfera de imagens novas. Os mais pungentes instantes ganham dentro dela uma expressão etérea. Os espetáculos que conhecemos, aí são vistos em transparência, como num sonho lúcido, ao mesmo tempo feliz e completamente desiludido. (MEIRELES, 1942, p. 27).

Exímia conhecedora das coisas do Oriente, Meireles é um dos primeiros nomes a chamar a atenção para a importância da China na obra de Pessanha. Ao colocá-lo como "mais próximo" do grupo modernista, a autora sensivelmente demonstrou acurado olhar crítico tanto no que diz respeito à obra do escritor coimbrão quanto à sua localização em relação ao modernismo. Camilo Pessanha antecipou muitos dos recursos poéticos usados por Fernando Pessoa e Mário de Sá-Carneiro, entretanto, vejamos aqui como a crítica abordou no decorrer dos anos a situação do poeta com o Simbolismo. 


\section{VOZES DO OUTONO: O POETA ESTRANHO}

A visão de Camilo Pessanha como o expoente do movimento simbolista português foi reproduzida sem maiores questionamentos desde a morte do autor até meados década de 80 do século passado. O livro de Esther de Lemos A 'Clepsidra' de Camilo Pessanha (1956), um marco da tradição crítica sobre o autor, foi o primeiro a consolidar e apresentar de modo profundo e sistematizado as relações de Pessanha com o Simbolismo. Desde então, os trabalhos que tentam tornar evidentes as relações entre Pessanha e Verlaine, por exemplo, tornaram-se incontáveis. Com as contribuições que a Literatura Comparada trouxe no decorrer do século XX (especialmente após a década de 1950 com o ensaio "A crise da literatura comparada", de René Wellek) a tentativa de espantar a "angústia da influência" e a revisão do uso de termos como "fonte e influência" contribuíram positivamente para que a crítica passasse a olhar de modo mais consciente para as obras. O peso dos clássicos passou a ser reavaliado, fomentando assim uma visão mais complexa da relação entre textos literários de diferentes épocas e culturas. Nesse sentido, a obra de Camilo Pessanha foi beneficiada, uma vez que a crítica passou a revisar a sua unânime classificação como marco simbolista lusitano.

O livro de 1982 de Barbara Spaggiari denota em seu título as leves mudanças na perspectiva crítica: $O$ Simbolismo na obra de Camilo Pessanha sutilmente revela que Pessanha passou a ser visto como um simbolista a seu modo. Nesse livro, a autora salienta que a obra do poeta português não se restringiu a uma mera imitação dos motivos e ritmos encontrados em Verlaine. Sobre o talento daquele afirmou:

Para além do modelo verlainiano, são também a música e o som em geral, os verdadeiros protagonistas da obra de Pessanha: as ressonâncias nasaladas da viola, o suspiro lamentoso de uma voz fantasma, o murmúrio longínquo das barcas, o bater obsessivo da chuva, as vozes além túmulo de um velho disco, a melodia atormentada de um violoncelo, são sons que evocam imagens e se traduzem em palavras, em ritmo de versos e em sucessão medida de sílabas. (SPAGGIARI, 1982, p. 13).

Assim, Pessanha teria ido além da simples cópia, recriando sobre os motivos do poeta francês a sua própria poética. João Camilo em sua crítica "A Clepsidra de Camilo Pessanha", 1894, feita para o número 10 da revista Persona, usa o termo "aproximação" para abordar as relações entre a obra do poeta coimbrão e do poeta francês. Olhar Pessanha por esse ângulo, tal 
como Spaggiari, redimensiona o trabalho do poeta, ressaltando que sua poesia não se restringiu à "influência" ou "herança": "conhecedor e admirador da poesia de seu tempo (...) é verdade que Camilo Pessanha não seguiu à letra as propostas de Verlaine”, e prossegue:

mas as modificações que Camilo Pessanha introduziu, ao nível de acentos no decassílabo, o partido que tirou do 'enjambement' e a variedade de ritmos e formas que utilizou justificam uma aproximação com o autor de Romances sans Paroles". (PESSANHA, 1984, p. 20).

As similaridades entre a poesia de Pessanha e a poesia do poeta francês são facilmente traçadas a partir de uma aproximação no modo de abordar o tema da fugacidade do tempo; todavia, atribuir que tal tópico na obra de Pessanha encontre fonte na obra de Verlaine é fechar os olhos a uma longa tradição de poetas portugueses da qual Camões é o pilar. Dessa forma, é importante recordar que já o poeta de Os Lusíadas, no espírito do século XVI, abordara a fugacidade da vida no soneto "Mudam-se os tempos, mudam-se as vontades".

No seguimento da corrente que consagrou o poeta de Clepsydra como o grande simbolista lusitano, encontra-se a crítica de Álvaro Cardoso Gomes, que o classifica como "legítimo herdeiro de Verlaine":

Mas de todos os poetas simbolistas do período o mais importante foi mesmo Camilo Pessanha, que, com sua única obra poética Clepsidra (1920), chegou até a influenciar Fernando Pessoa. Isso porque, ao contrário de Eugênio de Castro, por exemplo, soube como levar às últimas conseqüências a revolução simbolista em Portugal. Assim, de um lado, Pessanha é o legítimo herdeiro de Verlaine, com seus versos musicais que exploram as íntimas relações entre as sonoridades e os estados de alma mais íntimos, como vem expresso em seu poema "Violoncelo" (...)Mas, do outro lado, Camilo Pessanha é também o poeta que expressa o sofrimento frente à brevidade da vida, a incapacidade do homem de captar o que quer que seja da realidade circundante (...)Poeta refinado, manifestando em sua poesia o sentimento de uma dor cósmica, Camilo Pessanha soube dar como ninguém intensa força à palavra poética, explorada em todas as suas nuanças. (CARDOSO GOMES, 1994, p. 45-47).

Veja-se que a visão de Cardoso Gomes é bastante mais restrita que a de Spaggiari e de João Camilo no que concerne às relações da obra de Pessanha com a de Verlaine, todavia, o crítico chama a atenção para a importância do poeta coimbrão dentro do movimento modernista 
português, direção para a qual atentara Cecília Meireles em sua antologia. Álvaro Cardoso Gomes (1986, p. 14-16) distinguiu três correntes para o simbolismo português, Camilo Pessanha seria o maior representante da terceira, a qual partiria em busca de uma "expressão fluida, quase transparente" e cujo diálogo com Verlaine lhe atribuiria a evidente sugestividade dos versos.

Outro crítico que salientou a importante relação entre Camilo Pessanha e o modernismo português foi Óscar Lopes, segundo o qual o poeta teria produzido "o melhor conjunto de poemas simbolistas portugueses, que exerceram profunda influência na geração de Orpheu" (SARAIVA; LOPES, 2001, p. 977) e ainda sustenta que a obra de Pessanha seria a mais "pura" representação do simbolismo português. Gustavo Rubim, em seu livro Experiência da alucinação, a respeito do fato de Lopes ver em Pessanha tanto um precursor do modernismo quanto um exemplo puro de simbolista, escreveu:

Se é certo que nada nos força a ver nisto um flagrante de contradição, não o é menos que, por um lado, a "pureza cristalina" do simbolismo de Pessanha se torna problemática a partir do momento em que esse simbolismo se deixa ler melhor à luz do que lhe é estranho. (RUBIM, 1993, p. 75).

Assim, Gustavo Rubim em seu livro de 1993 fez o excelente trabalho de comentar detalhadamente o posicionamento de Pessanha sobre poesia e concomitantemente colocar em questão a avaliação de que o poeta da Clepsydra seria o maior expoente do simbolismo português. Desse modo, Rubim afirmou:

\footnotetext{
A avaliação, mais ou menos consensual, de Pessanha como maior dos simbolistas portugueses não tem, nesse sentido, outro valor que o de um enquadramento histórico-literário pouco rigoroso, já que nenhum dos que a subscrevem alguma vez chega a procurar demonstrar a plena coincidência ou identificação do poeta da Clepsidra com a poética que faz do símbolo a essência mesma da poesia. (Idem, p. 73).
}

O termo "simbolismo", portanto, teria sido empregado para a obra de Pessanha, segundo Gustavo Rubim, como “avaliação e classificação genérica, estilística e periodológica” e "acaba (ou começa) por funcionar como dispositivo de resistência a uma leitura que dê conta do que é singular na poesia e na poética de Pessanha, incluindo as diferenças e distâncias em relação a tudo o que aquele termo implica” (Idem, p. 74). 
Anna Balakian em The Symbolist moviment, 1977, inicia sua introdução afirmando que ainda que elusivo, o termo Simbolismo tornou-se uma etiqueta convencional para historiadores da literatura designarem a era pós-romântica. Fato que ao mesmo tempo propiciou um alvo para aqueles críticos literários que consideravam o Simbolismo como uma classificação artificial para escritores esparsos, separados uns dos outros em termos de nacionalidade, tempo e gênero literário (BALAKIAN, 1977, p. 3). Entretanto, em critérios estritos, a palavra Simbolism, para os franceses, continuava a denotar um período bem específico compreendido entre 1885 e 1895 cuja vanguarda teria como expoentes Baudelaire, Rimbaud, Verlaine e Mallarmé (Idem). A autora ainda chamou a atenção para o fato de que ao longo dos anos a crítica tentou delimitar a corrente simbolista de várias maneiras, tanto de modo cronológico quanto por meio da tentativa de demonstrar aspectos comuns entre poetas que se opunham ao Romantismo entre tantas outras classificações e separações.

Sob esse prisma, definir o que foi o Simbolismo tornou-se tarefa complexa. Nas palavras de Balakian, o excesso de possibilidades para o termo quase que o desqualifica totalmente enquanto rótulo literário (Idem, p. 5). Todavia a autora ressaltou que, apesar das complexidades, o uso do termo é importante uma vez que é algo perigoso deixar o autor em um "vácuo" e atribuir apenas às suas características pessoais a existência de traços que são, na verdade, a estilização de uma herança comum (Idem, p. 8).

Por um lado, abordar a obra de Camilo Pessanha como uma simples ramificação do Simbolismo ${ }^{6}$ francês e especificamente enquanto herança de Verlaine, é reduzir a arte do poeta português em relação à obra do poeta francês e ter como maior base de comparação apenas componentes formais. Por outro lado, não se trata de isolar Camilo Pessanha da experiência social e cultural de sua época, e sim de avaliar melhor e mais detalhadamente as relações do poeta com esse contexto. Conforme os estudos mais recentes de Gustavo Rubim e Paulo Franchetti, entre outros críticos, é possível verificar que a poesia de Pessanha não se restringiu à aproximação com o Simbolismo. É fato, segundo Balakian em The fiction of the poet, 1992, que o Simbolismo se espraiou para além das fronteiras de Paris e influenciou muitos poetas tendo, inclusive, sido muito popular nos anos de 1920. Assim certamente Pessanha terá mantido laços estreitos com o Simbolismo francês, mas o faz de modo assaz particular. Nesse sentido, a poesia de Pessanha se tornou algo único no cenário lusitano da época, mesclando os elementos

\footnotetext{
${ }^{6}$ Seguindo o raciocínio de Balakian, Simbolismo refere-se ao movimento francês que se deu em Paris entre 1885 e 1900 e simbolismo refere-se ao estilo simbolista fora dos limites cronológicos do movimento.
} 
simbolistas aos pré-modernistas e adicionando a isso uma invulgar dicção relacionada à estética oriental.

Por ora, vejamos o que há em Pessanha que seja diverso do Simbolismo. Gustavo Rubim mostrou-se bastante lúcido em sua supracitada argumentação. Se retomarmos o que alguns teóricos definiram como característica do simbolismo português poderemos perceber o quanto o poeta coimbrão também se afasta dessa vertente, o que dá validade à asserção de Rubim.

Para Massaud Moisés, por exemplo, a poesia simbolista portuguesa - fazendo jus ao seu projeto de sugestividade - ao repudiar uma linguagem direta, comum à prosa narrativa, mostrase apegada, ainda, à forma parnasiana, sofrendo influências do decadentismo francês e de um tipo de neogarretismo que a prende a um "tradicionalismo de base histórica e folclórica" (MOISÉS, 2005, p. 213-214).

Ao recobrar o supracitado texto de Pessanha sobre Fogaça, percebe-se que o poeta da Clepsydra, conforme análise anterior, repudiava certas aparências da época e quanto ao "tradicionalismo de base histórica e folclórica", não parece haver muitos exemplos na poesia de Camilo Pessanha.

Já Álvaro Cardoso Gomes, em $O$ simbolismo (1944), observou que o simbolismo português tem inclinação para a valorização do ambiente campesino, enquanto que o Simbolismo francês tende mais a um cariz urbano, cosmopolita (1986, p. 19). Quanto ao ambiente campesino, pode-se verificar que as paisagens de Pessanha são assaz "estranhas", não parecendo estritamente atreladas a nenhum desses dois traços (seja de ar campestre ou urbano). Veja-se o poema "Floriam por engano as rosas bravas", em que o aparente ambiente campesino emoldurado pelas rosas no frio é quebrado pela enrijecida presença de "acrópoles de gelo", que transportam o leitor para um ambiente fora de correlação seja com o campo seja com uma cidade cosmopolita do século XIX. A rosa brava, ou rosa canina, presente no poema, é uma flor nativa tanto da Europa quanto do noroeste da África e da Ásia oriental. A presença da mulher envolta em "pétalas" e a nebulosidade do entorno remetem, ainda, a estilos da tradicional pintura chinesa:

E sobre nós cai nupcial a neve,

Surda, em triunfo, pétalas, de leve Juncando o chão, na acrópole de gelos...

(PESSANHA, 1997, p. 84). 
Sendo assim, é plenamente bem colocada uma referência que Gustavo Rubim fez a Jorge de Sena. Este, ao fazer o quadro de uma imagem global da literatura portuguesa, referiu-se a Pessanha como um "simbolista estranho" (SENA apud RUBIM, 1993, p. 74). Rubim ainda sublinhou que "a valorização de Pessanha como o 'único e verdadeiro simbolista da literatura portuguesa' não impede que se reconheça, simultaneamente, a quase total ausência de símbolos no seu cancioneiro" (Idem, ibidem). O crítico reforçou seu posicionamento ao recordar que Esther de Lemos, em seu emblemático ensaio, afirmou que "em Pessanha são raros os símbolos fixos" (LEMOS apud RUBIM, 1993, p. 74).

Por tudo isso, são vários os fatores que problematizam a assunção de Pessanha como um simbolista apenas, sem considerar a sua relação com o modernismo - talvez Pessanha tenha sido o poeta lusitano de maior expressão e importância da virada do século XIX para o XX. Atribuir a ele o título de expoente máximo do simbolismo em Portugal terá sido um modo generoso de a crítica reconhecer a sua contribuição, todavia, o poeta tem, ao longo de todos esses anos, revelado que a sua complexidade ultrapassa a referida classificação. Por isso, a inserção do poeta coimbrão ao lado dos poetas de Orpheu é um ponto invulgar sobre a coletânea de Cecília Meireles, sendo ela pioneira em unir a modernidade de Pessanha à sua relação com a China. Este forte e ambíguo laço estabelecido com certa cultura chinesa, a meu ver, foi um pioneirismo de Pessanha e uma das nuances que torna a poesia de Pessanha tão peculiar.

No ensaio "Da caligrafia ao ideograma”, Gustavo Rubim minuciosamente explicita o fino e complexo conhecimento de Pessanha sobre a arte chinesa e o relaciona com a escrita do mesmo poeta. Sobre a visão do autor da Clepsydra acerca da caligrafia chinesa, escreve:

Trata-se de destacar o efeito do destaque que Pessanha concede à questão da escrita enquanto elemento capaz de diferenciar a China não só da Europa, mas "de todo o resto do mundo". (...) O primeiro passo dessa abertura à escrita chinesa na sua diferença irredutível dá-se aqui, com o simples registro da incompatibilidade entre a "escritura fonética" dos europeus e a arte caligráfica dos chineses. (...) Os europeus mal podem "compreender" a sua existência, limitados como estão pela estrutura de sua própria escrita. (RUBIM, 1993, p. $10)$.

Nesse sentido, Rubim realçou a importância do contato de Pessanha com a China abrindo espaço para pensar que o relevo que o poeta português deu à caligrafia enquanto a arte que é (e realmente o é para os chineses) indica uma possível conexão entre seu modo de escrever poesia e a arte da inscrição da caligrafia. 
A caligrafia chinesa graficamente compara-se à pintura devido a sua rica variedade de forma e esboço, ainda exibe o rítmico fluxo da música sem deixar de ser uma linguagem escrita. Nesse sentido, Gustavo Rubim torna evidente a importância do contato com a China para a obra do autor.

O aprofundamento da percepção de que há certa presença mandarim na poesia de Pessanha encontra apoio em dois ensaios de Paulo Franchetti, ambos parte do livro Nostalgia, exílio e melancolia: leituras de Camilo Pessanha, 2001. O primeiro, denominado "Uma poética da nostalgia", aborda a experiência de Pessanha ao deixar o país rumo a Macau. O texto, portanto, trata da "saudade":

ao longo desse duplo percurso, temporal e espacial, esse coágulo que somos nós perde um pouco de si, impregna aquilo que nos impressionou ou nos seduziu: algo se desprende de nós e fica para trás, e nós nos vamos assim dissolvendo ao longo dos eixos do tempo e do espaço. É o sentimento decorrente dessa percepção que o poeta denomina genericamente de saudade e que tem, no contexto em que surge, uma forma específica: menos do que uma perspectiva de recuperação de um bem perdido, é a consciência de que não é possível apreender as experiências e mantê-las, não é possível incorporálas à subjetividade. (FRANCHETTI, 2001, p. 16).

O texto de Franchetti é um denso comentário sobre um trecho de uma carta que Camilo Pessanha escrevera ao seu amigo Alberto Osório de Castro (1868 - 1946) em 30 de abril de 1894, aos 26 anos, pouco depois de chegar a Macau. O excerto da carta é o seguinte:

E eu que tinha saudades de quanto ia deixando, até de Barcelona, onde estive cinco dias, até de Colombo onde estive duas horas. Porque a gente é bem um grumo de sangue, que por toda a parte se vai desfazendo e vai ficando. (PESSANHA apud FRANCHETTI, 2001, p. 15).

Conforme Franchetti elabora seu argumento, evidencia-se o peso que a experiência da distância da pátria teve para Pessanha e como isso se consolidou na sua poesia. Evidencia-se assim a importância que a percepção e a vivência assumem em Camilo Pessanha. Confluem 
dois pontos cruciais: a experiência de Pessanha e a noção oriental da fugacidade da vida. ${ }^{7}$ A experiência do autor encontra alicerce em certo modo de confrontar a vida propagado por algumas das mais tradicionais culturas orientais, tais como hinduísmo e budismo. ${ }^{8}$ Franchetti cita o restante da carta em que Pessanha expõe seu sentimento sobre a notícia de que sua mãe estava muito doente. Segundo Franchetti: "sobressai o sentimento da perda do lar materno como lugar de referência" (Idem, p. 18)

Agora, que solidão a minha (...) já devem ter despejado o travesseiro que minha Mãe encheu de rosmaninho para eu dormir, já devem ter feito em cacos a pequena chávena da China em que minha Mãe me dava o café, já devem ter deitado ao lume a mesa de pinho em que minha Mãe me punha o jantar. Quem me dera poder ir acudir a todas estas tristes coisas. (Idem).

O crítico segue sua densa argumentação cujo foco é a relação com a pátria - retornarei a esse ponto mais adiante, quando abordar a vivência do Oriente em Pessanha e Cecília Meireles. Para o momento interessa a abertura que o crítico deu à importância da experiência do exílio para Pessanha ao relacionar o trecho acima ao poema "Quem poluiu, quem rasgou os meus lençóis de linho”. Desse modo, revela-se que vários temas de sua poesia seriam impossíveis sem a experiência da distância da pátria, que culmina, nesse caso, com a vivência de outra realidade, agora pautada pelo Oriente.

O segundo ensaio de Franchetti chama-se "O rastro de sangue", no qual analisa o poema “Quando voltei encontrei meus passos...”. Primeiramente, o crítico explora a primeira versão composta em 1895 e publicada em 1898 (FRANCHETTI, 2001, p. 40). A primeira variante do poema, portanto, foi escrita um ano após a chegada de Pessanha a Macau, o último terceto deste soneto, à época, terminava da seguinte maneira:

\section{O esforço inútil! E vem logo a maré}

\footnotetext{
${ }^{7}$ A questão da impermanência modifica-se um pouco do hinduísmo para o budismo. No hinduísmo há a ideia de atman, que seria algo fixo - uma verdade fundamental que existe dentro de cada um. Nesse sentido, diante da impermanência (anitya) haveria ainda algo em que alguém pudesse se fixar (o verdadeiro "eu"). Já para o budismo, a impermanência, identificada pelo conceito anicca (tradução para a língua Pali do termo sânscrito anitya), é parte dos três marcos da existência. O budismo, por sua vez, menciona que não há, nesse mundo, nada que seja permanente ou fixo. Como tudo está sujeito à mudança, a decadência é um componente inerente a todas as coisas, a existência é sempre um fluxo contínuo, um vir a ser, como um rio que flui. Essa noção está fortemente presente na poesia de Pessanha.

${ }^{8}$ É certo que a tradição greco-latina também tem sua expressão desse tipo de pensamento no estoicismo, por exemplo, todavia a abrangência e a atualidade do budismo e do hinduísmo justificam a sua importância na virada do século XIX para o XX. As leituras e traduções de textos das religiões da China, Índia e Japão naquele período se fortaleceram e adentraram o século XX.
} 
E apaga-vos. (Meus passos - para quê?)

- como um cão que lambe um rastro de sangue...

(PESSANHA apud FRANCHETTI, 2001, p. 39).

A ideia do "rastro de sangue" e do poema em geral em muito se conecta com o sentimento exposto por Pessanha na carta analisada no ensaio anteriormente citado, o poema parte de uma ideia simples, a da vida enquanto caminhada e aprofunda seus possíveis sentidos na constatação de que os momentos do passado estão ainda vivos, frescos na areia (FRANCHETTI, 2001, p. 43-44). A presença do sangue sublinha a vivacidade da memória representada pelos passos “ainda vivos" na areia. Franchetti apresenta outra versão do poema, datada de 1908, provavelmente, na qual, entre outras mudanças, a última estrofe surge refeita:

\section{Onde fostes? Meus passos! Para quê? \\ Até vir apagar-vos a maré, \\ Como um cão que lambe um rastro sangrento. \\ (PESSANHA apud FRANCHETTI, 2001, p. 49. Grifos meus).}

Esta versão nunca chegou a ser publicada e Franchetti avalia que aqui o poema ganhou um tom mais dramático, além de apontar para algumas mudanças na versificação. Em 1915, nos autógrafos que serviram de base para a Clepsydra de 1920, consta, ainda, uma terceira versão (FRANCHETTI, 2001, p. 50). Nesta, a última estrofe se constrói com uma mudança mais drástica:

Toda essa extensa pista - para quê?

Se há-de vir apagar-vos a maré,

Com as do novo rastro que começa...

(PESSANHA apud FRANCHETTI, 2001, p. 51).

Franchetti faz uma análise das alterações. Entretanto, por ora interessa salientar o trabalhoso trato do poeta na construção de seus versos. A persistente reescrita do mesmo poema por cerca 20 anos revela algumas transformações no sentido dos versos que podem estar diretamente ligadas à vivência de Pessanha e ao seu modo de interpretar algumas peculiaridades da vida, sublinha-se aqui a questão o tempo. A versão mais recente, feita depois de anos sobre o solo de Macau, mostra uma acurada e sutil relação com uma maneira mais diversa de conceber as ações humanas e sua inserção no tempo. O rastro apagado pela maré e que insiste em recomeçar, tolamente, para ser apagado mais uma vez.

O rastro, o sangue e a frieza da mulher são temáticas importantes que fazem parte das primeiras composições de Pessanha antes de sua ida a Macau. Veja-se o poema "Madalena", Jangada | nr. 14, jul/dez, 2019 | ISSN 2317-4722 
em que "os cabelos de rastros" de Madalena, que se enrolam ao seio, parecem ao mesmo tempo se confundir com o "Ensanguentado, enxovalhado, inútil," peito do eu lírico a talvez "Sangrar, poluir-se, ir de rastos na lama," (PESSANHA, 1997, p.174). De modo que os rastros do cabelo de Madalena levariam à "subjugação" na qual se encontra o eu lírico, como que a rastejar ensanguentado na lama. Tal frieza feminina se revela também em "Estátua":
E o meu ósculo ardente, alucinado,
Esfriou sobre o mármore correto
Desse entreaberto lábio gelado...
Desse lábio de mármore, discreto,
(Idem, p. 66).

Tais temáticas parecem se reconfigurar após a experiência da viagem marítima e da distância da pátria. Assim, as suas primeiras composições feitas longe de Portugal começam a carregar características que apontam para novos temas, como a passagem do tempo. Assomamse a isso as primeiras composições em que "os olhos" são elemento fundador dos sentidos do poema, como em "Paisagens de inverno":

Ó meu coração, torna para trás.

Onde vais a correr, desatinado?

Meus olhos incendidos que o pecado

Queimou... Voltai, horas de paz.

(Idem, p. 82. Grifos meus).

Ainda no mesmo poema: "- Cismai meus olhos como dois velhinhos" e "Sossegai, esfriai, olhos febris." "Paisagens de inverno" também evoca a passagem do tempo: "Extintas primaveras evocai-as: / — Já vai florir o pomar das macieiras,”. A passagem do tempo começa a ser incorporada por meio da representação das estações, algo muito comum à poesia chinesa, de modo que em outro poema também redigido em 1894, "Passou o outono", a percepção da mudança constante também é dada por uma paisagem. Nesse caso, o outono dá lugar ao inverno e, dessa vez, a mulher é figurada juntamente à água, conforme demais poemas escritos em Macau, como "Vênus".

"Fonógrafo" é outro poema cuja composição, segundo Daniel Pires, é de 1894 (PIRES, 2012, p. 43-44). Ao final deste poema o verso "Primavera. Manhã. Que eflúvio de violetas!", marcado pela recorrência de palavras divididas por pontos finais (detalhe utilizado pelo modernismo para marcar a velocidade) e pela composição de uma paisagem "idílica", dialoga 
diretamente com uma sorte de poemas orientais, chineses e japoneses. Em especial "Que eflúvio de violetas" traz traços de Kireji (palavra que pode servir para encerrar o sentido do haicai). É notável o pioneirismo do poema de Pessanha, que composto em 1894 e reescrito em 1896 carrega em si mostras que estão presentes em composições tidas como modernas. O último verso não apresenta verbos, e quebra com a métrica decassilábica que vigorava no decorrer do poema:

(...)

Muda o registo, eis uma barcarola:

Lírios, lírios, águas do rio, a lua...

Ante o Seu corpo o sonho meu flutua

Sobre um paul - extática corola.

Muda outra vez: gorjeios, estribilhos

Dum clarim de oiro - o cheiro de junquilhos,

Vívido e agro! — tocando a alvorada...

Cessou. E, amorosa, a alma das cornetas

Quebrou-se agora orvalhada e velada.

Primavera. Manhã. Que eflúvio de violetas!

(PESSANHA, 1997, p. 68).

De certa forma, o haicai pode ser um elemento de conexão no qual o ocidental encontrou referências que serviram ao retrato da velocidade moderna. Em "Fonógrafo" a estranheza do aparelho fonográfico e a sua velocidade são o foco da ação poética. Portanto, Pessanha possivelmente tenha aproveitado alguma leitura da literatura do Oriente em seu poema. ${ }^{9}$

\section{CONCLUSÃO}

Ao considerarmos a relevância que o haiku teve para o modernismo brasileiro, em termos de ideal "de registro direto da sensação e do sentimento e como forma adequada ao tempo rápido

\footnotetext{
${ }^{9}$ Em 1895 Vesceslau de Moraes, amigo de Pessanha, escreveu Traços do Extremo Oriente, e desde 1894 também fizera parte do corpo docente do Liceu de Macau, juntamente com o amigo poeta (a essa altura Moraes já conhecera o Japão e viria a ser o primeiro a traduzir haicai para a língua portuguesa).
} 
o presente" (FRANCHETTI, 2008), ${ }^{10}$ torna-se plausível que alguns traços modernos da poesia de Pessanha tenham encontrado seu berço nos modelos poéticos orientais, ainda mais se avaliarmos que esses versos compostos por períodos curtíssimos espaçados pelo ponto final não estavam presentes em seus primeiros escritos.

Sendo assim, quando vive a experiência de Macau, a poesia do autor de Clepsydra passa a dar forma embrionária ao que viria a ser central para a expressão em poesia modernista portuguesa. $\mathrm{O}$ contato com as culturas do Oriente passa a ser incorporado à sua arte, entretanto essa incorporação se dá de modo muito diverso do que fizera um Eça de Queiroz, por exemplo (vide $O$ Mandarim): os ares orientais inspirados por Pessanha são expirados pela sua voz, de modo que já não é mais possível delinear os limites entre o que ele trouxe de Portugal e o que ele aprendia na China. Tudo se une para formar a expressão única de um poeta ímpar, aliás, de um sujeito ímpar. A sua poesia, portanto, passa a ser expressão de identidade, tentativa de recolha de fragmentos esparsos, "Dentinhos que o vaivém desengastara... Conchas, pedrinhas, pedacinhos de ossos". O seu olhar descontruído para o tempo (pairar no tempo, parar o tempo) e a fragmentação da construção de uma identidade lírica são aspectos importantes tanto da heteronímia pessoana quanto da formação de um personagem central do modernismo português como Lúcio, das Confissões de Lúcio (Mário de Sá-Carneiro).

Camilo Pessanha foi professor de filosofia do Liceu de Macau e certamente não deixou de conhecer a cultura e filosofias locais, demonstrando saber, inclusive, o nome das deidades; veja-se o caso em que manda de presente ao amigo Antonio Pinto de Miranda Guedes uma representação de Avalokiteshvara, conforme a carta datada de Macau, 20 de fevereiro de 1912:

A figurinha creio que o senhor Miranda Guedes a reconhecerá: é a Kun-Iam dos chineses, Avalo-Kitesvara dos hindus, - úbere de inexaurível piedade para todos os budistas, e que fundamentalmente não difere daquele "Cheia de

10 Em 1925, no prefácio ao Poesia Pau Brasil, de Oswald de Andrade, Paulo Prado inclui um terceto em francês a que chama "haicai". Todavia, o haicai colado por Paulo Prado no prefácio não se tratava de um haicai, tampouco se tratava de poesia japonesa, era, sim, um terceto retirado do poema "Art Poetique", de Joseph Seguin. Sobre a escolha do haicai como síntese de alguns preceitos do movimento modernista brasileiro, Paulo Franchetti escreve em "O Haicai no Brasil", 2008:

O haicai japonês aparece, então, como ideal de coloquialidade, de registro direto da sensação e do sentimento e como forma adequada ao tempo rápido do presente. $\mathrm{E}$ também como modelo literário não-europeu para o projeto nacionalista brasileiro, que visava, nas suas palavras, "romper os laços que nos amarram desde o nascimento à velha Europa, decadente e esgotada". (FRANCHETTI, 2008, In. Alea vol.10 no.2 Rio de Janeiro July/Dec). 
graça, Mãe de misericórdia" do soneto de Antero e dos místicos enternecimentos da nossa adolescência. (PESSANHA, 2012, p. 265).

Dessa maneira, de justificável a coerência que busquemos, dentre todas as complexas partes que formam a poesia de Pessanha, as presenças orientais em sua obra. Há alguns delineamentos de sua escrita que ainda não foram contemplados com a extensão e profundidade e a relação do poeta com a China certamente elucida muitas de suas características que foram lidas apenas à sombra do Simbolismo. A multiplicidade e pluralidade dos sentidos de sua obra e os aspectos díspares da sua personalidade pedem um olhar mais amplo e atento aos detalhes que a experiência oriental possivelmente lhe tenha dado.

Agradeço à CAPES, ao Professor Gustavo Rubim e à Professora Joana Matos Frias.

\section{REFERÊNCIAS BIBLIOGRÁFICAS}

BALAKIAN, A. The fiction of the poet. Princeton: Princeton University Press, 1992. The Symbolist movement a critical appraisal. New York: Random House, 1967.

CANDIDO, A. Formação da literatura brasileira. Belo Horizonte: Itatiaia, 2000.

CARDOSO GOMES, Á. O simbolismo. São Paulo: Ática, 1994.

CARVALHO PRATA, M. A. Imprensa estudantil de Coimbra: Repertório analítico (século XIX). v. 1. Coimbra: Imprensa da Universidade de Coimbra, 2006.

CASTRO, E. "Prefácio da primeira edição de Oaristos". In. GOMES, Á. C. A estética simbolista. São Paulo: Cultrix, 1985.

FRANCHETTI, P. “O Haikai no Brasil”. In: Alea, vol.10, n.2, Rio de Janeiro, July/Dec, 2008. Nostalgia, Exílio e Melancolia: leituras de Camilo Pessanha. São Paulo: Edusp, 2001.

LEMOS, E. A Clepsidra de Camilo Pessanha. Lisboa: Verbo, 1981.

MEIRELES, C. Poetas Novos de Portugal. Rio de Janeiro: Dois Mundos, 1944.

MOISÉS, M. A literatura portuguesa. São Paulo: Cultrix, 2005.

MURICY, A. Panorama do simbolismo brasileiro. Vol. I. São Paulo: Perspectiva, 1987.

PEREIRA, J.C.S. "Camilo Pessanha e a transmutação simbolista". In: História Crítica da Literatura Portuguesa. Vol. VII - Do Fim-de-século ao Modernismo. Lisboa/São Paulo: Editorial Verbo, p. 129-139, 1995.

"Romantismo tardio e surto neo-romântico no fim-de-século". In: Revista Humanitas, vol 50. Coimbra: Imprensa da Universidade de Coimbra, 1998. 
PESSANHA, C. “Crónica da Alta”. In: A Crítica, 1. a série, n. 2, março de 1888.

Correspondência, dedicatórias e outros textos. São Paulo: Unicamp, 2012.

Macau, 1992.

. Clepsidra. Edição crítica, fixação do texto, introdução e notas de Barbara Spaggiari. Porto: Lello e Irmão, 1997.

PIRES, D. "Cronologia da vida e da obra de Camilo Pessanha". In: PESSANHA, C. Correspondência, dedicatórias e outros textos. São Paulo: Unicamp, 2012.

RAMOS, F. Trindade Coelho homem de letras: o contista, o esteta e o pedagogista. Coimbra: Acta Universitatis Conimbrigensis, 1947.

RUBIM, G. Experiência da alucinação: Camilo Pessanha e a questão da poesia. Lisboa: Caminho, 1993.

SARAIVA, A.J; LOPES, Ó. História da literatura portuguesa. Porto: Porto Editora, 2001.

SPAGGIARI, B. O simbolismo na obra de Camilo Pessanha. Carlos Moura (trad). Lisboa: Instituto da Cultura e da Língua Portuguesa Publicações, 1982. 